\title{
Effectiveness of psychodrama group therapy on pupils with mathematics anxiety
}

\author{
Gstrein Dorothea
}

Published online: 3 December 2015

(C) The Author(s) 2015. This article is published with open access at Springerlink.com

\begin{abstract}
The present study focuses on the effectiveness of psychodrama group therapy on adolescents suffering from mathematics anxiety. Five secondary school pupils in Merano, aged 17-19 years, took part in 10 group sessions of $90 \mathrm{~min}$, held weekly over a period of about 3 months. The changes generated by psychodrama therapy in the pupils' problem areas, such as, high stress levels before tests, impaired working memory, low self-esteem and motivation to learn mathematics, were measured with the help of the Personal Questionnaire (Elliott and Shapiro, Simplified personal questionnaire procedure, 1999) and the Self-efficacy scaleMathematics, two quantitative measuring instruments, and with the Client Change Interview, a qualitative measuring instrument. The results of the data collected indicate that psychodrama treatment brought forth significant changes in some pupils' problem areas.
\end{abstract}

Keywords Psychodrama - Mathematics anxiety · Mathematics self-efficacy · Working memory - Motivation to learn mathematics · Personal questionnaire · Self-efficacy scale - mathematics · Client change interview

\section{Wirksamkeit der Psychodramagruppentherapie bei Schülern mit Angst vor Mathematik}

Zusammenfassung Die vorliegende Studie beschäftigt sich mit der Wirksamkeit der Psychodramagruppentherapie bei Jugendlichen, die unter Angst vor Mathematik leiden. Fünf SchülerInnen einer Oberschule in Meran, Südtirol, im Alter von 17-19 Jahren, nahmen an 10 Gruppensitzungen von jeweils 90 Minuten

G. Dorothea $(\square)$

Winkelweg 4,

39012 Meran, Italy

e-mail: dorotheagstrein@hotmail.com 
teil. Die Sitzungen wurden wöchentlich über einen Zeitraum von drei Monaten abgehalten. Die Veränderungen, die durch die Psychodramagruppentherapie in den von den SchülerInnen genannten Problembereichen, wie hohe Belastung vor Tests, beeinträchtigtes Arbeitsgedächtnis, geringer Selbstwert und mangelnde Motivation Mathematik zu lernen, erzielt wurden, wurden mit Hilfe des Personal Questionnaire (Elliott and Shapiro Simplified personal questionnaire procedure, 1999) und der Selbstwirksamkeitsskala-Mathematik, zwei quantitativen Messinstrumenten und mit dem Client Change Interview, einem qualitativen Messinstrument gemessen. Die Auswertung der gesammelten Daten deutet darauf hin, dass Psychodramagruppentherapie bei einigen SchülerInnen zu signifikanten Veränderungen in einzelnen Problembereichen geführt hat.

Schlüsselwörter Psychodrama · Angst vor Mathematik - Selbstwirksamkeit Mathematik · Arbeitsgedächtnis · Motivation Mathematik zu lernen · Personal Questionnaire $\cdot$ Selbstwirksamkeitsskala-Mathematik $\cdot$ Client Change Interview

\section{Introduction}

The topic of mathematics anxiety is receiving increasing attention within the psychological literature (Ma 1999; Ashcraft and Kirk 2001; Ashcraft and Krause 2007; Ashcraft and Moore 2009; Lyons and Beilock 2012), especially because of its often serious and detrimental influence on educational achievements. However, scientific papers investigating or showing the treatment effects of different kinds of therapies on mathematics anxiety are extremely rare if not inexistent. So far no study has been conducted on the effectiveness of psychodrama therapy on people suffering from this form of anxiety.

Mathematics anxiety seems to affect a notable proportion of the school age population and adults in post-secondary education (Ashcraft and Ridley 2005) and it does not appear to be restricted to specific parts of the world, since it is well-known both in western and in Asian countries. Mathematics seems to be the most feared and avoided subject among pupils in primary and secondary schools as well as among college students (Yeo 2004).

\section{Mathematics anxiety}

The first attempt to define and to deal with mathematics anxiety was made by M. F. Gough, an elementary school teacher. After seeing her students struggle with mathematics she wrote an article with the title "Mathemaphobia: Causes and Treatments" (1954). Since then mathematics anxiety has been studied more widely and various researchers have provided different definitions of this disorder. Richardson and Suinn (1972, p. 551), for instance, describe it as a state that involves "feelings of tensions and anxiety that interfere with the manipulation of numbers and the solving of mathematical problems in a wide variety of ordinary life and academic situations". They offered the first instrument that is specifically designed to measure mathematics anxi- 
ety, the "Mathematics Anxiety Rating Scale (MARS)", which is still in use today. Glen E. Hunt (1985, p. 32) describes mathematics anxiety as "the panic, helplessness, paralysis and mental disorganization that arises among some people when they are required to solve a mathematical problem". Ashcraft's (2002, p. 181) shorter and more recent definition of mathematics anxiety, reads as follows "a feeling of tension, apprehension, or fear that interferes with math performance".

Even if a notable proportion of the school age population and of adults suffers from mathematics anxiety, presently, it is not acknowledged by the Diagnostic and Statistical Manual of Mental Disorders (American Psychiatric Association 1994). Hopko et al. (1998) suggested that mathematics anxiety should be considered a genuine phobia and should be added to the category of specific phobias, since it meets all the standard diagnostic criteria for such reactions. An individual who suffers from mathematics anxiety is intent to avoid the phobic situation and if he cannot avoid it, he endures it with intense anxiety or distress. The avoidance of such a situation, anxious anticipation, or emotional stress in the feared situation, all significantly interfere with the individual's normal routine or academic functioning.

So far the most frequently investigated research questions regarding mathematics anxiety have been "How does mathematics anxiety develop?", "When does mathematics anxiety develop?", "Are there any gender differences in mathematics anxiety?", "Which role does working memory play in mathematics anxiety?", "Is there a correlation between mathematics anxiety and mathematics performance?".

The first research question, regarding the development of mathematics phobia, can be answered in two different ways. Maloney et al. (2010) have explored the extent to which anxiety and basic numerical abilities are present in adults. In their study they show that fundamental skills, like counting and number comparison, are correlated with mathematics anxiety also in adults. Also Rubinstein and Tannock (2010) have come to similar findings, namely that adults show deficiencies in basic mathematics abilities. Considering this, one could assume that if adults, children's role models, show base level process deficiencies, the effects may be exaggerated in children. In this way the presence of mathematics anxiety among adults could be seen as a possible reason for the development of math anxiety in children.

Another distinct possibility is that mathematic anxious teachers might convey their anxiety to their pupils. Hembree, (1990) when exploring societal roles in the development of mathematics anxiety, reported that college students who were preparing to be elementary teachers, showed a higher prevalence of mathematics anxiety than other students. Following this track and adding the hypotheses that in many western countries primary school teachers are almost exclusively female and form the group with the highest prevalence of math anxiety, Beilock et al. (2010) measured the mathematics anxiety of first and second grade teachers. They also studied the mathematics performance of their pupils at the beginning and end of the school year. Since children of this age are very susceptible to same-gender stereotypes, they predicted that girls would especially be affected by their female teachers' mathematics anxiety. The study's findings suggest that there is a strong correlation between the teachers' mathematics anxiety and the girls' mathematics performance, while the boys' performance kept unaltered. 
Apart from this, relatively stable gender-related mathematics attitudes and stereotypes may also have an effect on females' mathematics performances. Gunderson et al. (2012) showed that both, teachers and parents, hold strong gender-related mathematics beliefs, especially emphasizing negative stereotypes for females. A continuous confrontation with this kind of stereotypes may additionally contribute to higher mathematics anxiety and lower mathematics achievements among females.

Two meta-analyses on mathematics anxiety have researched the relationships between mathematics anxiety and other personal and educational factors (Hembree 1990; Ma 1999). According to these studies mathematics anxiety is strongly correlated with mathematics performance and with other anxiety measures, in particular with test anxiety.

Liebert and Morris (1967) were the first to research test anxiety in general. According to them test anxiety consists of an emotional element and a cognitive element. A pupil or student, who reacts affectively to a test situation, may experience increased blood pressure and heart rate, sweaty palms, dizziness, dry mouth or trembling hands. A student, whose cognition is affected by a test situation, may have feelings of low self-efficacy, indecision, a sense of confusion, worry, poor concentration or defeatist self-talk. Their theory proposes an interference model of test anxiety. According to this theory the recall of prior learning is disturbed by test anxiety. If facts or in the case of mathematics, formulas, cannot be recalled, it is understandable that mathematics performance can be considerably degraded.

Eyseneck and Calvo (1992) proposed a model of the anxiety-to-performance relationship in cognitive tasks. Their theory has become known as the "processing efficiency theory". It claims that frequent intrusive thoughts and constantly present worry characteristics of high anxiety compete with the ongoing cognitive task for the limited processing resources of working memory. The result of such competition is either a slowing of performance or a decline in accuracy, both leading to performance deficits. The role of students' working memory, which seems to be particularly affected by mathematics anxiety, has been investigated by more recent studies (Ashcraft and Kirk 2001, Ashcraft and Krause 2007).

Ashcraft and Moore (2009) have studied the relationship between mathematics anxiety and desirable attitudes towards mathematics. The results of their research suggest that mathematics anxiety is strongly connected to avoidance strategies. An obvious but unfortunate consequence of continually avoiding math tasks is that students with high mathematics anxiety tend to end up with reduced math competence and lower achievement. In this way a vicious circle is preprogrammed since lower achievement will lead to lower enjoyment and lower self-confidence in math tasks and will finally result in poor motivation to learn math. The consequence of lower motivation may be inadequate progress, which could soon prompt negative feedback from parents and teachers resulting in negative self-perceptions.

A recent study by Lyons and Beilock (2012) shows the effect of mathematics anxiety on some regions of the human brain. The researchers have found out that this form of anxiety triggers the same brain activity like that of the physical sensation of pain. This study seems to provide the first neural evidence indicating the nature of the subjective experience of mathematics anxiety. The data collected suggest that simply by anticipating an unpleasant event, like an immediately forthcoming math- 
ematics test, a math-anxious individual would show activation of neural regions that are involved in pain processing.

The list of negative effects and consequences of mathematics anxiety on the school age population is long. It ranges from lower enjoyment and lower self-confidence, avoidance tendencies, poor performance to negative feedbacks and even sensations of pain. It is no wonder that people experiencing these feelings and inadequacies are biased away from taking math classes or math-related career paths.

\section{Psychodrama and mathematics anxiety}

Research on different forms of therapy and their specific interventions, which are apt to alleviate pupils' and students' anxiety related to mathematics, are practically inexistent. Currently there are no studies that show the effectiveness of psychodrama as a treatment for adolescents who suffer from mathematics anxiety. This study can therefore be considered a first attempt to bring some light into a completely dark and unexplored area of research. The aim of this study is to investigate the effectiveness of psychodrama group therapy on adolescents who have mathematics anxiety.

Moreno (1946) provided some precious thoughts about anxiety. He was convinced that anxiety and spontaneity exist at opposite ends of the continuum, and that anxiety sets in because spontaneity is missing. When spontaneity is restrained our view of possibilities and choices is restricted. Within the perception of restricted choices and options we function in a robotic fashion with our creativity lying dormant. Creative acts, however, can generate changes, can produce unknown results. Moreno was convinced of "spontaneity-creativity as a propelling force in human progress" (1946, p. xv). Spontaneity would provide the energy that can help a person to respond adequately to a new situation, or would generate the capacity to respond in a new way to an old situation.

Pupils and students suffering from mathematics anxiety definitely lack spontaneity and experience limited choices of reactions. Especially before and in test situations, when their worrisome thoughts grow out of proportion; they are locked at one end of the continuum, at the anxiety end.

Prior to undertaking this study, the belief was that psychodrama group sessions would give the students the opportunity to enhance their creativity and to enable them to generate new responses to old and hindering situations. The basic concepts of psychodrama therapy, such as the re-enactment of a painful experience and a possible correction in the "surplus reality", or role reversal allowing a different perspective (Moreno and Moreno 1955) or feedback of fellow-students sharing the problem, should have healing effects on the participants. In the safe and supportive environment of the group sessions the participants would be encouraged to use their creative power and get the opportunity to try out new and more effective roles and behaviors. 


\section{Method}

The aim of this study is to determine the effectiveness of psychodrama group therapy on adolescents who have mathematics anxiety.

In October 2013 I contacted some of my mathematics colleagues and asked them to inform their pupils about the study and to hand them out the recruitment letter explaining the aim and the procedure of the project. Seven pupils struggling with mathematics expressed their interest in participating in the study and were invited to a personal interview of about 60-90 min before the beginning of the group sessions. They stated their reasons for taking part in the study and they talked about their problems related to mathematics. This resulted in a very detailed, individualized list of problems forming their Personal Questionnaire (PQ), an expanded target complaint measure, developed by Robert Elliott (Elliott and Shapiro 1999). In order to guarantee the anonymity of the research participants they added their individual code consisting of their mothers' day and month of birth to their PQs (e.g. 1203).

The most frequently mentioned problems regarded their nervousness before a math test, their increased stress level, their inability to concentrate during the test, as well as continuous defeatist self-talk. Some pupils reported somatic disorders, stomach ache or headache or sleep disorders before a math test. All of the pupils interviewed said that their motivation to learn mathematics was rather low, that they often compared their performances with schoolmates and that their perceived selfefficacy related to mathematics was extremely low.

From this list of struggles, the following research questions were asked and formed the basis of the research, in relation to whether - psychodrama group therapy is effective:

1. in reducing somatic and physical symptoms

2. in reducing stress levels and promoting functioning of working memory to promote ability to ignore distracting and worrying thoughts.

3. in changing pupils' attitudes or relationship with mathematics

4. in promoting pupils' sense of self efficacy

\subsection{Participants}

Participants from the 3rd, 4th and 5th forms of the German-speaking high school, Fachoberschule für Tourismus und Biotechnologie "Marie Curie" in Merano (South Tyrol, Italy) were recruited for this study. The information about the project was passed on to the mathematics teachers and 7 pupils, 4 female and 3 male pupils aged between 17 and 19 volunteered to take part in the study and gave their informed consent. Parents' consent was needed for two participants, who had not been of legal age by the beginning of the project. Full data are available for 5 participants, 2 boys (all the students' names have been changed - Peter and Robert) and 3 girls (Monika, Caroline and Samantha) since two pupils, a girl and a boy did not come to the first two sessions and then decided not to take part in the project. 


\subsection{Procedure and measuring instruments}

After the initial interviews the group sessions started. The first session took place on 20th November 2013. The meetings were held weekly on Wednesday afternoons, a school-free afternoon, in the school's art room and lasted about 90 min each. The only school-related advantage of the participants was the recognition of $4 \mathrm{~h}$ of "elective course". The group sessions were conducted within a time span of almost 3 months and ended on 12th February 2014. Only one pupil was present at all the ten meetings, the others attended six to eight sessions.

In this study three different instruments were used to measure possible changes due to psychodrama group therapy, Elliott's PQ and the Self-efficacy Scale-Mathematics, created by myself, based on the "General Self-Efficacy Scale (GSE)" by Schwarzer and Jerusalem (1999), two quantitative measurement tools, and the Client Change Interview (Elliott et al. 2003), a qualitative measuring instrument.

While the PQ is a widely used questionnaire concentrating on the problems of the participants on a 7 -point Likert scale $(1=$ totally disagree to $7=$ totally agree $)$, the Self-efficacy Scale-Mathematics is a questionnaire consisting of positive statements on a 4 -point Likert scale $(1=$ totally disagree to $4=$ totally agree $)$.

Typical statements in the pupils' PQs were "Before a math test I get very nervous", or "When I get a negative grade in a math test I would like to pack it all in" or "Some nights before a math test I find it hard to fall asleep". The four most frequently mentioned problem areas seemed to be impaired working memory due to high stress level, somatic disorders, low motivation to learn mathematics as well as low perceived self-efficacy and faith in oneself related to mathematics.

The Self-efficacy Scale Scale-Mathematics, on the other hand, includes only positive statements, such as "I can fully concentrate on the math test" or "I am highly motivated to understand and learn mathematics". The PQ was filled in at the beginning of every single group session as well as in the follow-up session by each participant, the Self-efficacy Scale-Mathematics at the first group meeting, at the very last and at the follow-up survey.

Follow-up data were collected in the second and third week of May 2014, generally known as a "hot" testing period at school. The students filled in their PQ, the Self-efficacy Scale-Mathematics for the last time, and were then invited to the Client Change Interview. In this semi-structured interview, lasting about an hour per participant, the pupils were asked about possible changes during or after the therapy, attributions to changes, helpful and non-helpful aspects of the therapy and possible suggestions for further improvement of psychodrama sessions.

The students were informed that the data collected with their PQs and their Selfefficacy Scale-Mathematics, would be analyzed and evaluated by a third person not involved either in the group sessions or in the study as a whole.

\subsection{Group sessions}

At the beginning of the group sessions a solid social framework was provided. This framework included a few simple rules, which were set up at the first meeting. The first rule regarded secrecy. Any disclosure made in the group would be considered 
privileged information. The respect for group members and for their privacy was of paramount importance. The second rule referred to the extent to which every group member would like to bring himself into play. Every member was given the right to decide individually how much of his feelings and thoughts he/she would like to share with others. Mutual respect and generally acknowledged communication rules made up the third basic rule, punctuality the fourth.

This social framework was set up in order to guarantee a safe environment in which pupils could begin their journey of personal empowerment, discovery of selfworth and expanding consciousness by using psychodrama. Especially in the first session personal exposure and risk taking of single members was to be avoided. None of the pupils had heard about psychodrama before and the idea of playing together or putting personal experiences on stage was something the participants felt rather embarrassed about.

At the beginning of each session the participants filled in their PQ, in the first and last session also their Self-efficacy Scale-Mathematics.

In the first session the pupils were given the opportunity to get to know each other as group members. This was done with the help of name games followed by some sociometric exercises, related to information about their family, age or hobbies. The last of these exercises included a visual presentation of the pupils' personal reflection on attitudes towards mathematics on a concretised 10-point line ranging from "very negative attitude towards mathematics"- 1 point marked by a chair in a corner of the room - to "totally positive attitude towards mathematics" - 10 points marked by another chair in the opposite corner. The session ended with the subjects' feedback about their immediate feelings and thoughts, first impressions and expectations for the coming sessions.

Subsequent sessions started with the pupils completing their PQs and individual statements to the group about their present states, mental and physical, and anything particular or important that may have happened during the previous week, be it something related to mathematics or not. The next stage of each session included a warm-up, which was followed by a group play, or a protagonist's play. If the session comprised a protagonist play, the group members involved in the play gave their role feedback, the others imparted the observations they had made. Then there was time for the participants' sharings, time for the exchange of similar experiences the single group members had made in their lives. The sessions always ended with a general feedback of the participants about the session and about their current state of mind.

A detailed description based on the minutes of two meetings follows in order to illustrate the work that has been done with the adolescents during the group sessions.

\section{3rd Group Session-27th November 2013}

At the beginning of the session all the participants fill in their PQs and speak about last week's experiences. While four students say that nothing particular has happened, Robert feels terribly frustrated because he just got back a maths test, very negative, grade 4 (Italian grades go from 3 to 10, 3 being totally negative and 10 excellent). An imaginary current "well-being line" related to mathematics is set up and all the pupils position themselves on a particular spot on the line from 1-very bad-to 10 extremely well. They all explain which point on the line they stand on and what they 
feel on this particular spot. Robert positions himself at "around 3", saying that he feels very bad there, his anger mounting. He describes the anger he felt when he saw his grade 4 on the on-line register. He says he was "so furious that he could have strangled someone". In a situation like this he would like to hit somebody or something, or he would like to do something totally crazy like riding his motorbike at breakneck speed or to race downhill on his bike. He could also pick something up and throw it against the wall. Robert chooses a participant to play the role of his anger. In the role of his anger he explores and tries out various ways that could reduce its impetus. He takes a pillow and as quick as lightening throws it on the floor, repeating this action several times. He is asked if there is anything else that could help him release his aggression. He would like to play the "downhill race". A course is established, chairs and benches marking the obstacles. Robert starts his downhill race, jumping over the obstacles and racing around. After three rounds he gives up, he feels exhausted, worn out. He watches his double repeating the actions and says "This looks silly".

When asked "What would be helpful for you now, what would do you good?" he answers "tranquility" and "time". He chooses two female participants, one of them representing "tranquility", the other "time" and places them about three meters behind his anger. In the role of "tranquility" Robert claims that he feels totally neglected and that would need much more attention. In the role of "time" he expresses his neutrality, "time" can wait, is in no hurry. Robert is rather surprised about these statements, since these qualities seem to be totally unknown to him. In the role of his anger he invites his newly discovered qualities "tranquility" and his "time" to come closer and he even turns round to look at them. In the last role reversal with his anger Robert states that he does not know the quality of these new characteristics very well, but they seem to be friendly and helpful and he would like to get to know them better. He seems calmer and more relaxed than at the beginning of the session.

After the protagonist's play the fellow-pupils give their role feedback and their sharing. They are encouraged to speak about their own experiences of anger related to mathematics or to other situations. The session is concluded enquiring about the protagonist's feelings and his present state of mind.

\section{5th Group session-18th December 2013}

First the participants fill in their PQs and inform the group about their condition in general and related to mathematics in particular. A warm-up focusing on feelings follows. The pupils are asked to walk through the room, to think first of a scene in which they felt sad, to adapt their posture, walking pace, gestures and facial expressions to this situation; scenes and situations related to other feelings, anger, joy and fear follow. Each group member briefly tells the others which scene has come to his mind. In the last situation the students are asked to remember a fearful situation they have experienced that has somehow to do with mathematics.

Caroline talks about a scene that happened 4 years ago, at the beginning of her first year of secondary education. Everything was new for her, new school, new classmates and she got back a math test and saw the mark on it, 3, totally negative. The teacher handed the paper out without any comment. She felt like crying then, but she did not, then she started feeling dizzy, everything around her was blurred. She felt sick and could not react. 
The scene is put on the stage. The imaginary classroom is set up, Caroline chooses one participant to act as her double, another to play the teacher's role and a third to play her classmates. On stage, when playing the original scene, Caroline quickly feels the dizziness again and cannot understand the teacher, who just gives her back the paper, not saying a single word of encouragement. That is what she would have needed the most, a teacher comforting her, telling her that this is not the end of the world.

Caroline shows how the teacher should have reacted, how he should have comforted her, what he should have said, so that she would have felt better. The original scene is played again, this time incorporating the "corrections" proposed by Caroline. She gets the paper back, the teacher reacts supportively and encouragingly, comforts her and even offers her extra lessons. In this scene Caroline feels understood in her sorrow and does not feel dejected or low-spirited at all. In the role of her classmates she first feels terribly sorry for Caroline but unable to react, paralyzed. In the second scene when the teacher reacts sympathetically she does not feel any tension any more.

After concluding the scene the other participants give their role feedback and their sharing. All of them know the range of difficult feelings when seeing a totally negative mark on their test papers, when a teacher acts inappropriately and uncaringly, knowing that they just have to put away the feelings and come to terms with the frustration, sadness and grief.

\section{Results}

Full data are available for 5 participants, 2 male and 3 female pupils, all of whom have mathematics anxiety, their symptoms being present but transient. The symptoms are expected reactions to psychosocial stressors, namely solving mathematical problems, particularly in written forms of assessment, none of the participants shows any impairment in other school or social functioning.

\subsection{Self-efficacy scale- mathematics}

Data were collected on three different dates, on 20th November 2013, the first group session, on 12th February 2014, the tenth and last session, and in May 2014, the follow-up survey. In general the analysis of the data collected with this measuring instrument does not show clear trends or significant changes in the pupils' attitudes, feelings or behavior. Therefore only two exemplary graphs will be shown to illustrate the data of the Self-efficacy Scale-Mathematics.

The scores of the whole group regarding the pupils' motivation towards mathematics expressed by statement 8 "My motivation to understand and study mathematics is great" are represented in the graph below. It shows that the subjects have differently assessed their motivation at the three points of data collection, but no clear trend can be recorded (Fig. 1).

The next graph shows the scores related to statement 10 "If a mathematical problem arises, I can solve it by myself". This statement focuses on the pupils' rating of their ability to come to terms with mathematical problems. None of participants 
Fig. 1 Trend motivation Statement 8

Fig. 2 Trend self-efficacy faith in oneself Statement 10
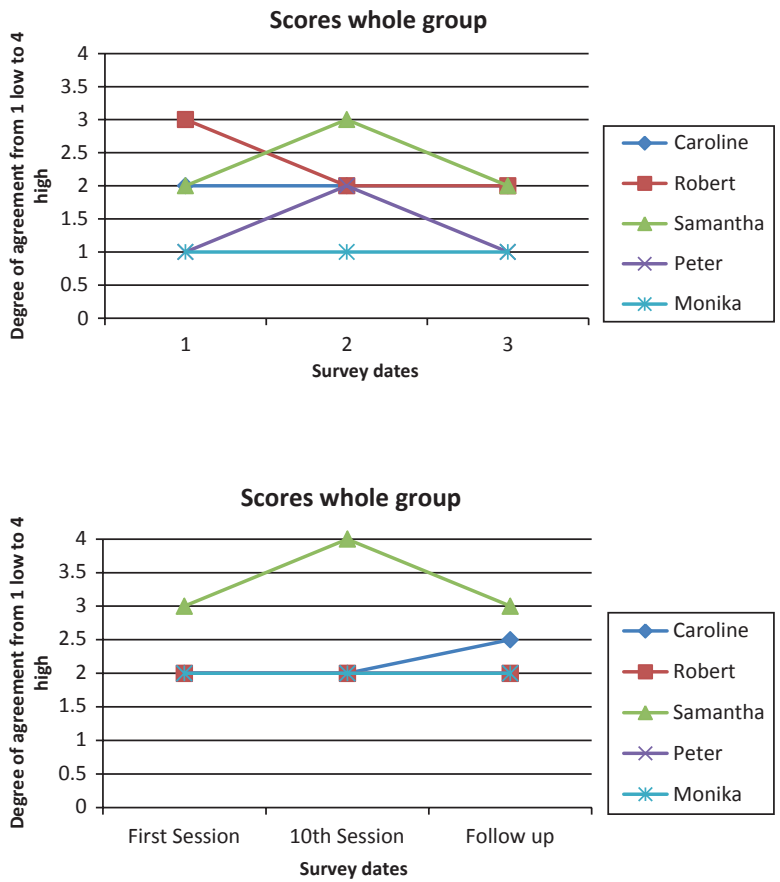

seems to feel that he has been able to increase his trust in himself related to the solution of mathematical problems. Only one pupil's scores have increased by 1 point at the 2 nd measuring period but have decreased again in the follow-up survey (Fig. 2).

\subsection{Personal questionnaire}

In the PQs the pupils have made from 7 to 10 statements related to their problems connected with mathematics. The first data were recorded on 20th November 2013, further data followed weekly or whenever a group session was held until the end of the group sessions on 12th February 2014. Follow-up data were collected from 15th to 25th May, shortly before the Client Change Interview.

Since only one participant was present at the total number of group sessions, one attended only 6 sessions and others from 7 to 9 , the number of measuring points varies. The analyses of the data collected by the PQ shows that no single problem stated in any of the participants' questionnaires has remained unaltered over the treatment period, some changes, even if small ones, can be found in all of them.

The statements that show only slight changes from the beginning of the group sessions to the follow-up survey, which make up the majority, will not be presented. The following graphs show considerable differences between the pupils' self-assessment recorded on the first session and the follow-up survey. The statements regard effects of psychodrama training on self-efficacy or belief in oneself, on somatic and sleep disorder, on working memory and on motivation. 
Fig. 3 self-efficacy PQ Statement 7

Fig. 4 Self-efficacy PQ Statement 9
Samantha:

"I tell myself that I simply can't do maths."

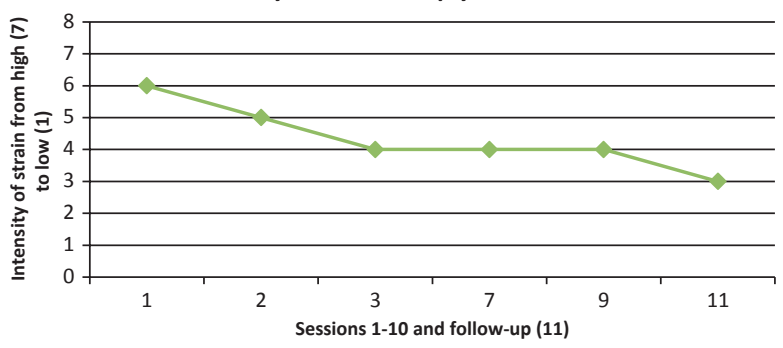

Caroline:

"I tell myself. I am simply too stupid to do maths."

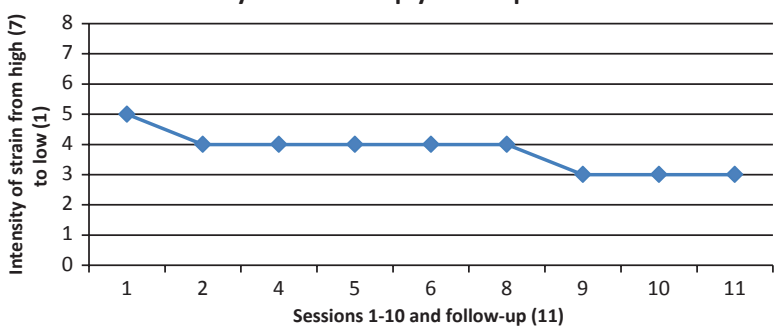

The following two graphs show the scores of Samantha and Caroline related to the evaluation of their self-efficacy in mathematics or their ability to deal with mathematical problems (Fig. 3, 4).

Both these graphs show significant changes in the pupils' perceived self-efficacy or trust in themselves. The scores related to the intensity of strain show a decrease of 3 points in one graph and of 2 points in the other.

In the next two graphs the changes recorded in the PQs of Samantha and Robert related to somatic and sleep disorders are shown. In the first, the stress caused by difficulties in falling asleep and by restless sleep is reduced by 2 points. In the second Robert, who mentioned strain because of a headache in combination with a math test, does not seem to consider this problem as seriously as before the psychodrama training (Fig. 5, 6).

The following graphs show the changes in the pupils' PQs related to the functioning of their working memory. In the course of the psychodrama group sessions the scores of these two pupils, mentioning first the risk of blackouts and second the difficulty to control impulses, show a noteworthy decrease from 5 to 3 points and from 5 to 2 points, respectively (Fig. 7, 8).

The following two graphs show the results of two pupils regarding their motivation to study mathematics. Both students seem to find it easier to study math or to be able to better cope with negative grades in this subject after the psychodrama group sessions. Samantha shows a decrease in the intensity of strain related to her motivation from 6 to 3 points, the other pupil's scores decrease from 5 to 2 regarding his negative perception of being motivated to study math (Fig. 9, 10). 
Fig. 5 Sleep disorder PQ Statement 4

Fig. 6 Somatic disorder PQ Statement 4

Fig. 7 Working memory PQ Statement 6
Samantha:

"Some nights before a math test I find it hard to fall asleep and my sleep is restless."

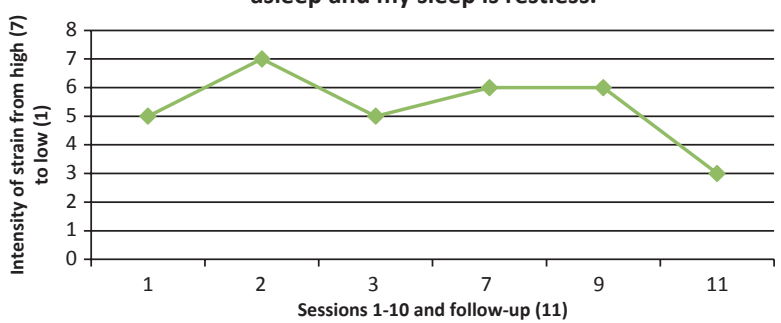

Robert:

"I sometimes have a headache before and during maths tests."

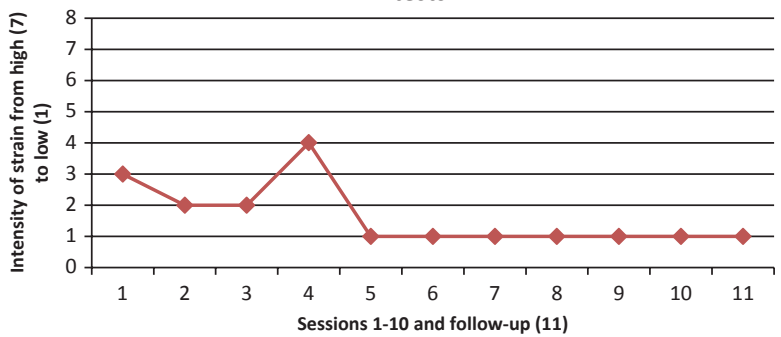

Peter:

"When I am stressed I may have a blackout."

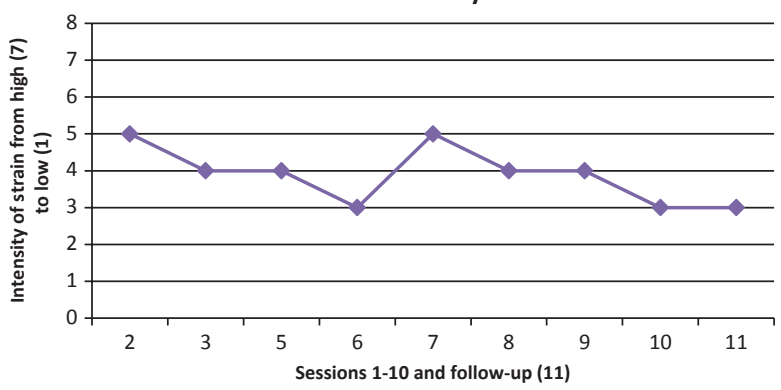

\subsection{Client change interview}

The Client Change Interview was conducted with the students in mid-May 2014. In the interviews the students all stated that the psychodrama group sessions had had some positive effects. The first positive effect mentioned was regarding their improved performance in mathematics, then the different attitude to mathematics, next their thoughts related to the subject and the reduced stress level experienced when sitting a mathematics exam.

All the participants reported that their grades had improved, some considerably. One participant, who had always got positive grades, but suffered from blackouts, stated that no blackout had occurred since the beginning of the sessions. 
Fig. 8 Working memory PQ Statement 7

Fig. 9 Motivation PP Statement 1

Fig. 10 Motivation PQ Statement 9
Robert:

"In some situations I am livid and laden, about to explode and can't concentrate."

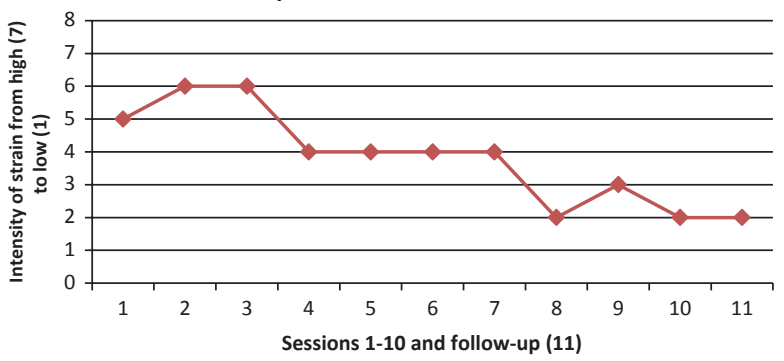

Samantha:

"I try to get a positive attitude to maths, which sometimes is really hard."

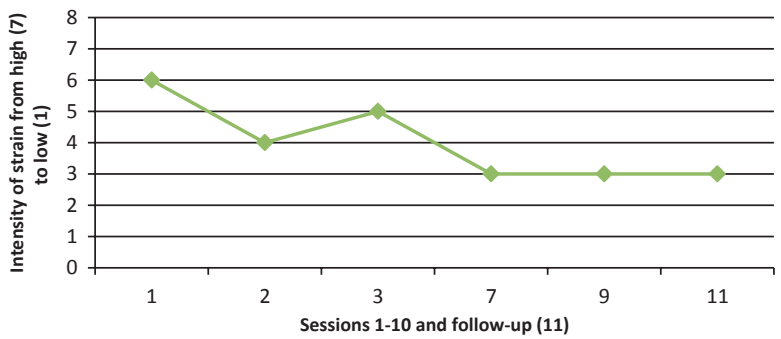

Robert:

"With every negative grade I get, my motivation to do something gets lower."

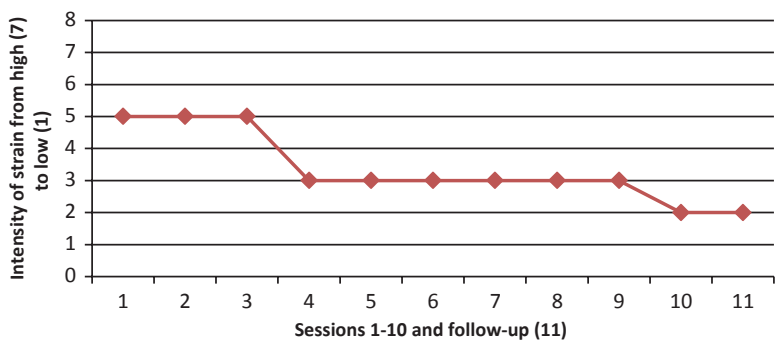

Regarding motivation to learn mathematics only one student convincingly declared that this goal had been reached. None of the other participants said that the psychodrama training had fundamentally changed their motivation to study mathematics, however, all the students reported that some changes in their attitude towards mathematics had occurred. They had the impression that the constant confrontation with their problems regarding mathematics seemed to have led to a new awareness and a more relaxed way of dealing with mathematics in general and that the pressure or the 
fear often felt before tests had become less. All the participants reported that negative and worrisome thoughts about tests, causing great distress before the psychodrama training had become less frequent now.

When asked about the reasons for these changes, four pupils said that the fact that they had got the opportunity to talk about their problem so openly with other people had been very helpful. They had become aware that others shared their difficulties.

None of the subjects could think of any important events in their private life, positive experiences, such as happy new relationships that could have been the cause of changes, or negative experiences, like the breaking-up of relationships or the loss of something or somebody, that could have contributed to the fact that they could not have made full use of the psychodrama training, respectively.

While two participants think that the changes could have occurred also without the psychodrama group sessions, three of them were convinced that without psychodrama the changes would not have happened. All of them confirmed that the changes were very important to them, one pupil considered them as extremely important.

When asked about the personal traits that may have helped the pupils make the changes, multiple answers were "will power", "patience", "positive thoughts", "open-mindedness" and "flexibility".

The most frequent answers to the question about non-helpful aspects of the psychodrama group training listed by the participants focused on framework conditions, especially limited time resources and school stress.

\section{Discussion}

This study is a modest contribution to the developing literature in adolescent psychodrama research. The pupils taking part in this study are functioning within the normal range therefore large effect sizes cannot be expected.

Apart from this, the study has several limitations, the first being the small experimental group size (5 participants). Another limitation is the low number of group sessions. 10 group sessions can hardly generate significant changes in all the participants' problem areas. A further weakness consists in the fact that only one follow-up survey was made. In this way it was not possible to establish the possible long-term effects of group participation benefits.

Another weak point is using the quantitative instrument of the Self-efficacy Scale-Mathematics used in this work. The questionnaire, specifically created especially for this work, lacks scientific validation and has not been able to show any significant changes in the pupils' problem areas. This may in part be due to the fact that on a 4-point Likert scale participants tend to choose central scores rather than scores on the extremes, in part it may be explained by the fact that pupils are definitely not used to thinking positively when assessing their mathematics abilities.

The statements made by the participants during the Client Change Interview must be considered with particular care. Firstly, because they may tend to please the person conducting the research, in this case probably even more since I am a teacher at the school; secondly, because they may have found it more appropriate to speak about positive aspects to please the interviewer, rather than pointing out negative aspects. 
The analyses of the data collected with the PQs and the statements made in the Client Change Interview mostly correspond. A comparison of the data collected with the Self-efficacy Scale-Mathematics and the PQs shows that the results do not correspond, in particular as far as motivation is regarded. While in the Self-efficacy Scale-Mathematics no increase in the motivation can be noticed, in the PQs two students show a remarkable change in their attitude towards the subject.

The findings of the present work in relation to the research questions mentioned before can be summed up as follows.

As far as somatic problems, such as headache and sleep disorder, are concerned, the analyses of the PQs of two pupils shows that the intensity of strain has decreased from 3 to 1 and from 5 to 3 respectively, which can be considered significant changes.

The next research question was related to the effectiveness of psychodrama group therapy related to a reduction of the pupils' stress level, which would have positive effects on their working memory. The scores of the participant who mentioned the risk of blackouts in test situations in his PQ decreased from 5 to 3, another significant change. In the Client Change Interview he even said that no such blackout had occurred in the course of this school year.

Another pupil's scores, who according to statement 7 of his Personal Problem Questionnaire "feels livid and laden, about to explode", show a decrease of the stress level from 5 to 2 . This change may be due to the protagonist play of this particular participant focusing on his aggression when getting a negative mark in a math test.

As far as positive effects of psychodrama group sessions on the pupils' motivation are concerned, two of them seem to have managed to increase their motivation of studying mathematics.

Statements in the PQs regarding the participants' self-efficacy in mathematics resulting in greater trust in their own ability were mentioned by two students. Both seem to have been able to reduce their lack of confidence and to increase their perceived self-efficacy.

Naturally other unknown factors not mentioned or considered by the participants may have influenced the outcomes of the pupils' scores in the PQs.

Although several improvements would be needed in future studies on the effectiveness of psychodrama on pupils with mathematics anxiety the results based on the data at hand are encouraging. The changes emerging from the PQs and the statements made in the Client Change Interview seem to support the initial hypotheses that psychodrama group sessions can have positive effects on the participants' motivation and on their physical well-being. Moreover, they seem to be able to enhance their self-efficacy related to mathematics and to improve their mathematics performance by reducing their stress levels.

The changes shown in the pupils' PQs and stated in the interviews suggest that the group therapy provided a medium in which the participants could expose their feelings, could share their partly traumatic early experiences with mathematics with other students. Through the frequent sharing given by other group members the participants definitely got the feeling that they were not alone with their specific problem, mathematics anxiety.

It can be assumed that re-enacting an stressful life experience has brought the pupils in contact with painful emotions, and this seems to be a crucial step to make 
corrective emotional experiences (Gassmann and Grawe 2006). Especially the technique of role reversal, of stepping into the role of someone else or into an element or quality unknown so far, seems to have been important for self-integration and for interpersonal socialization.

The representation of fantasies and real experiences on the psychodramatic stage seems to have offered them the opportunity to re-live and re-experience an unpleasant event in their life, offering a "correction" of the experience in the surplus reality. Through psychodrama their repeated worrisome thoughts, their fearful images and pictures, have been rendered alterable (Fürst 2004, p. 245).

Apart from these changes another goal of the study was reached, namely to enable the participants to gain insight in their personal problems and to get fully aware of them. During the group sessions, as some of them pointed out also in the Client Change Interview, they certainly became more aware of their strengths and weaknesses, in other words, they have got to know themselves better. In the Client Change Interview the pupils also stated that the feedback they got from their fellow-students improved their awareness of not seeing events, feelings and thoughts objectively and of not recognizing their own strengths. Sometimes this may have been painful, but it seems to have initiated a process of reflection, which allows the pupils to work on their behavioral weaknesses.

Another aim may have been achieved with this study. The presence of mathematics anxiety in classrooms and the variety of problems it causes can definitely be confirmed. Every mathematics teacher that recognizes this problem may get more and more aware of the influence of this specific anxiety on the pupils' mathematics performance. While the group sessions were being held I talked to the two mathematics teachers who were most helpful when recruiting pupils. By taking their pupils' anxiety seriously and offering them help they made a first step towards change. In the course of the treatment both teachers confirmed that some pupils' attitude towards mathematics had changed and that their performance had started to improve. Immordino-Yang and Damasio (2007, p. 9) have got to the heart of the issue stating "When we educators fail to appreciate the importance of students' emotions, we fail to appreciate a critical force in students' learning".

\section{Outlook}

The present study can be considered an exploratory case study showing the effects of psychodrama on adolescents with mathematics anxiety. The findings of this work highlight the need for further research in this field to clarify the conditions under which psychodrama group sessions are maximally effective. More refined measuring instruments should be developed and adopted in order to get more accordant results.

The number of subjects taking part in the group sessions should be increased, in this way the collected data would become more meaningful. More group sessions focusing on the participants' specific problems and experiences with mathematics could generate additional material for analyses. 
In conclusion, it can be said that more time, more group sessions and a higher number of participants, would be needed to generate significant changes in deeprooted convictions of the pupils' negative beliefs related to mathematics.

Open Access This article is distributed under the terms of the Creative Commons Attribution License which permits any use, distribution, and reproduction in any medium, provided the original author(s) and the source are credited.

\section{References}

American Psychiatric Association (1994). Diagnostic and statistical manual of mental disorders (4th ed.). Washington, DC: American Psychiatric Association.

Ashcraft, M. (2002). Math anxiety: Personal, educational, and cognitive consequences. Directions in Psychological Science, 11, 181-185.

Ashcraft, M., \& Kirk, E. (2001). The relationships among working memory, math anxiety, and performance. Journal of Experimental Psychology: General, 130(2), 224-237.

Ashcraft, M., \& Krause, J. (2007). Working memory, math performance, and math anxiety. Psychonomic Bulletin \& Review, 3(2), 243-248.

Ashcraft, M., \& Moore, A. (2009). Mathematics anxiety and the affective drop in performance. Journal of Psychoeducational Assessment, 27, 197-205.

Ashcraft, M. H., \& Ridley, K. S. (2005). Math anxiety and its cognitive consequences: A tutorial review. In: J. Campbell (Ed.): The handbook of mathematical cognition (pp. 315-327). New York: Psychology Press.

Beilock, S., Gunderson, E., Ramirez, G., \& Levine, S. (2010). Female teachers' math anxiety affects girls' math achievement. Proceedings of the National Academy of Sciences, 107, 1860-1863.

Elliott, R., \& Shapiro, D. (1999). Simplified personal questionnaire procedure. Toledo: University of Toledo.

Elliott, R., Slatick, E., \& Urman, M. (2003). Qualitative change process research on psychotherapy: Alternative strategies. In J. Frommer \& D. Rennie (Eds.), The methodology of qualitative psychotherapy research. Lengerich: Pabst Science Publishers.

Eyseneck, M., \& Calvo, M. (1992). Anxiety and performance: The processing efficiency theory. Cognition and Emotion, 6, 409-434.

Fürst, J., Ottomeyer, K., \& Pruckner, H. (Eds.). (2004). Psychodramatherapie. Wien: Facultas Verlag.

Gassmann, D., \& Grawe, K. (2006). General change mechanisms: The relation between problem activation and resource activation in successful and unsuccessful therapeutic interactions. Clinical Psychology and Psychotherapy, 13, 1-11.

Gough, M. (1954). Mathemaphobia: Causes and treatment. The Clearing House, 28(5), 290-294.

Gunderson, E., Ramirez, G., Levine, S., \& Beilock, S. (2012). The role of parents and teachers in the development of gender-related math attitudes. Sex Roles, 66, 153-166.

Hembree, R. (1990). The nature, effect and relief of mathematics anxiety. Journal for Research in Mathematics Education, 21, 33-46.

Hopko, D., Ashcraft, M., Gute, J., Ruggiero, K., \& Lewis, C. (1998). Mathematics anxiety and working memory: Support for the existence of a deficient inhibition mechanism. Journal of Anxiety Disorders, 12(4), 343-355.

Hunt, G. E. (1985). Math anxiety - where do we go from here? Focus on Learning Problems in Mathematics, 7(2), 29-40.

Immordino-Yang, H., \& Damasio, A. (2007). We feel, therefore we learn: The relevance of affective and social neuroscience to education. Mind, Brain, and Education, 1(1), 3-10.

Liebert, R., \& Morris, L. (1967). Cognitive and emotional components of test anxiety: A distinction and some initial data. Psychological Reports, 20,975-978.

Lyons, I., \& Beilock, S. (2012) When Math Hurts: Math Anxiety Predicts Pain Network Activation in Anticipation of Doing Math. http://www.plosone.org/article/info:doi/10.1371/journal.pone.0048076. Accessed 14 April 2014. 
Ma, X. (1999). A meta-analysis of the relationship between anxiety toward mathematics and achievement in mathematics. Journal for Research in Mathematics Education, 30, 520-541.

Maloney, E., Ansari, D., \& Fugelsang, J. (2010). The effect of mathematics anxiety on the processing of numerical magnitude. Quarterly Journal of Experimental Psychology, 64, 10-16.

Moreno, J. L. (1946). Psychodrama (Vol. I. p. xii). New York: Beacon House.

Moreno, J. L., \& Moreno, Z. (1955). Discovery of the spontaneous man with special emphasis upon the technique of role reversal. Group Psychotherapy, 8, 103-129. (Reprinted in 1959, Psychodrama, Vol. 2, New York: Beacon House, 135-158.).

Richardson, F., \& Suinn, R. (1972). The mathematics anxiety rating scale: Psychometric data. Journal of Counseling Psychology, 19(6), 551-554.

Rubinstein, O., \& Tannock, R. (2010). Mathematics anxiety in children with developmental dyscalculia. Behavioral and Brain Functions, 6: 46. http://www.ncbi.nlm.nih.gov/pmc/articles/PMC2913999/. Accessed 15 May 2014.

Schwarzer, R., \& Jerusalem, M. (1999). Skalen zur Erfassung von Lehrer- und Schülermerkmalen. Dokumentation der psychometrischen Verfahren im Rahmen der Wissenschaftlichen Begleitung des Modellversuchs Selbstwirksame Schulen. Berlin: Freie Universität.

Yeo, K. (2004). Do high ability students have mathematics anxiety? Journal of Science and Mathematics Education in S.E. Asia, 27(2), 135-152.

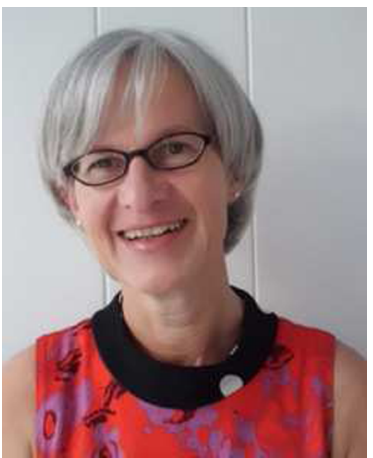

Gstrein Dorothea, 1958, Psychologist, Psychodramatist, Teacher of English at "Fachoberschule für Tourismus und Biotechnologie Marie Curie" Merano 